\title{
Consanguinity, cardiac arrest, hearing impairment, and ECG abnormalities: counselling pitfalls in the Romano-Ward syndrome
}

\author{
William Reardon, Neil Lewis, Helen E Hughes
}

\begin{abstract}
Genetic counselling in the autosomal dominant condition of the RomanoWard syndrome might be assumed to be relatively straightforward. The problems posed by consanguinity, deafness, and subclinical gene carriers in a pedigree with this condition have caused us to reevaluate this view. The diagnostic and management difficulties which may attend this potentially fatal condition are highlighted by our experience with this family.

(f Med Genet 1993;30:325-7)
\end{abstract}

The QT interval on a standard 12 lead ECG denotes the time taken for ventricular depolarisation and repolarisation. ${ }^{1}$ Since these electrophysiological phenomena may vary with heart rate, QT interval is usually expressed as QTc, which incorporates a correction factor to allow for this variation. ${ }^{2}$ The upper limit for the duration of QTc is given as 0.44 seconds. $^{3}$ Prolongation of the QT interval above this level is positively correlated with an increased incidence of ventricular arrhythmias.

An overlap between QT interval prolongation and genetic disease is recognised in two conditions. The Romano-Ward syndrome ${ }^{45}$ (McKusick No 192500) ${ }^{6}$ is an autosomal dominant condition characterised by QT interval prolongation which may, in a minority of affected subjects, present with syncopal episodes. The syndrome of Jervell and Lange-
Nielsen ${ }^{7}$ (McKusick No 220400) describes the association of congenital deafness and QT interval prolongation. In contrast to the Romano-Ward syndrome, the syndrome of Jervell and Lange-Nielsen is inherited in an autosomal recessive manner, but QT interval prolongation was noted as an inconstant feature of the obligate heterozygote state. $^{8}$ Both conditions are associated with a high incidence of childhood mortality owing to the inherent instability of cardiac rhythm.

These conditions would appear to be individually well defined with little overlap between them. Equally, genetic counselling in families with either condition would seem to be relatively simple with little cause for confusion. Here, we present a pedigree in which the association of consanguinity, hearing impairment, and QT interval prolongation in some subjects created considerable diagnostic confusion and raised difficult counselling issues for the clinicians involved.

\section{Case reports}

The family came to attention when IV.4 (figure) had a cardiac arrest at the age of 4 years, suffering irreversible brain damage. Subsequent investigation showed a prolonged QTc of 0.49 seconds prompting more widespread investigation of other family members. Although asymptomatic, IV.5 was found to have a QTc comparable to that of his sister and was treated with beta blockade.
Institute of Medical Genetics, University Hospital of Wales, Heath Park, Cardifi CF4 4XN.

W Reardon

W Reardon
H E Hughes

\section{Department of} Cardiology,

University Hospital of Wales, Cardiff CF4 4XN.

N Lewis

Correspondence to Dr Reardon, Mothercare Department of Paediatric Genetics and Fetal Medicine, Institute of Child Health, 30 Guilford Street, London WC1N 1EH.

Received 21 May 1992. Revised version accepted 17 August 1992.

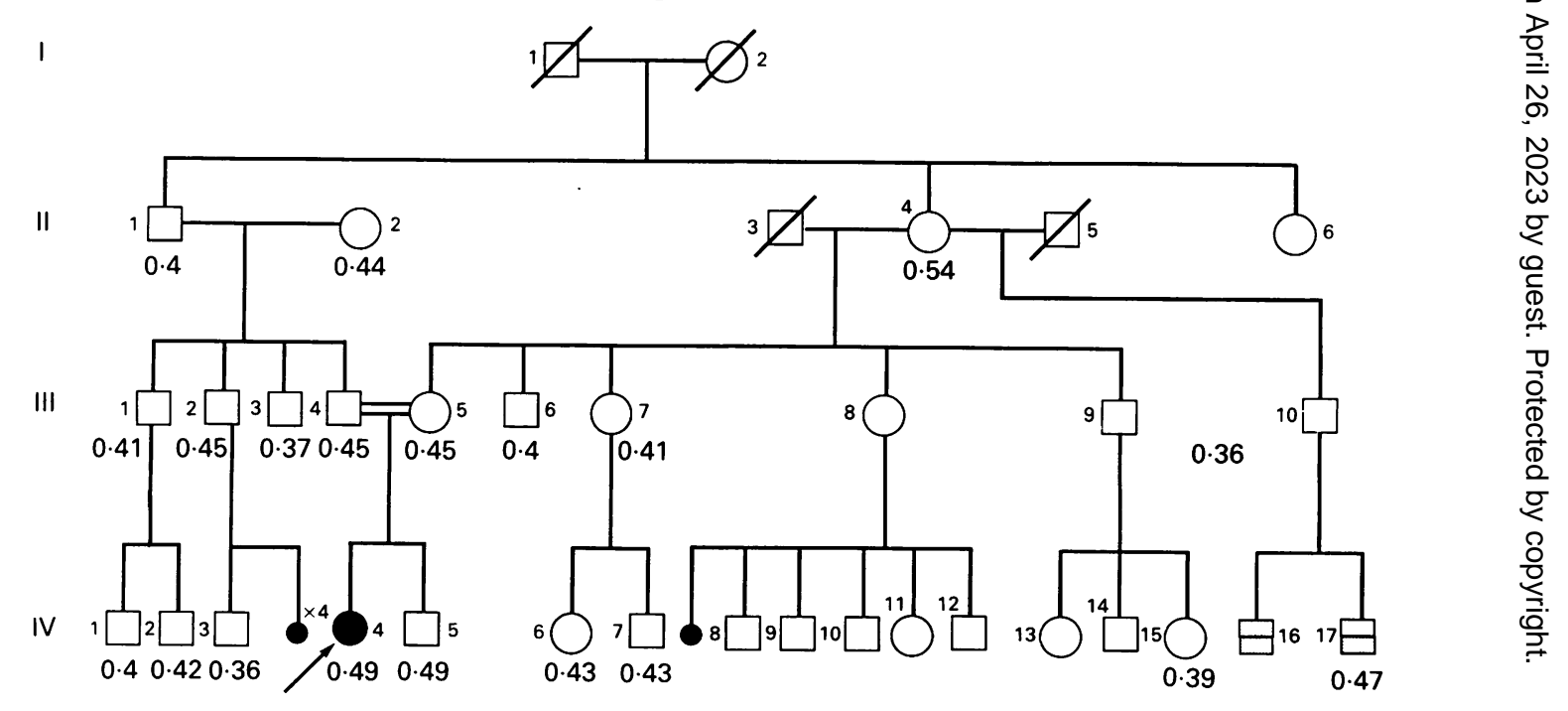

Sensorineural deafness

The pedigree showing QTcs of key subjects. 
Electrocardiographic investigation of the consanguineous parents of the proband (III. 4 and III.5) showed QTc just exceeding the limits of normality. Both were entirely asymptomatic. However, QTc in II·4, the maternal grandmother, was grossly abnormal at 0.54 seconds. Her brother, II 1 (also the paternal grandfather), was normal with QTc of $0 \cdot 4$, but his wife's (II.2) QTc was variously reported as ranging from 0.44 to 0.53 seconds, thus extending into the abnormal range. Abnormally prolonged QT intervals were a feature in several other members of both paternal and maternal families (figure).

The parents of these children, III 4 and III.5, were first cousins (figure), and both were reported to have a slight but significant dip in their hearing threshold at $4000 \mathrm{~Hz}$. Further significant audiological abnormalities were noted in the brothers IV 16 and IV $\cdot 17$, both of whom had bilateral high tone sensorineural hearing loss of mild to moderate degree with some evidence of low tone conductive loss. Similar observations were made in their grandmother, II.4. Minor deviations from normal audiological function were present in several other members of generation III but in all cases there was a positive history of occupational noise exposure which was thought to be consistent with the abnormalities observed.

\section{Discussion}

Accurate diagnosis is an essential prerequisite to meaningful genetic counselling. The formidable counselling problem in this family stemmed from the several diagnostic possibilities. Romano-Ward syndrome initially appeared to be the likely diagnosis in view of the QTc prolongation in II $\cdot 4$, her daughter (III.5), and her grandchildren (IV.4 and IV.5). However, the father of the proband (III.4) and his brother (III.2) also had QTc prolongation, apparently inherited from their mother (II-2), while their father had a normal QTc. This opened the possibility that Romano-Ward syndrome might be independently segregating in both the maternal and paternal families of IV.4 and IV.5, whose prolonged QTc intervals could reflect homozygous function of the gene.

An alternative hypothesis was that patients IV 16 and IV 17 had Jervell and Lange-Nielsen syndrome. The QTc prolongation in IV 17 was consistent with this diagnosis and both children had a moderate degree of deafness. The widespread QTc prolongation observed throughout the other family members could reflect the normally hearing heterozygous state, which has been known to cause QTc prolongation. ${ }^{89}$ Under this model IV 4 would represent a symptomatic heterozygote, although no comparable data appear to have been published relating to this particular syndrome. This diagnostic conundrum led to a total review of genetic and cardiological publications relating to QTc prolongation.

The segregation analysis of Fraser provides overriding positive evidence for autosomal recessive inheritance in Jervell and Lange-Niel- sen syndrome. ${ }^{10}$ Moreover, in all affected homozygotes, Fraser showed a severe bilateral sensorineural hearing loss. QT prolongation in heterozygotes appears to be a rare observation, being noted in one obligate carrier parent and one possible gene carrier sib (a priori risk of $50 \%)$ in one report ${ }^{8}$ and, possibly, in an obligate carrier parent in a separate report. ${ }^{9}$ Thus, the degree of deafness and the widespread occurrence of QT prolongation in this family were at odds with the published data on Jervell and Lange-Nielsen syndrome.

However, deafness and QT prolongation have been reported together in situations other than the Jervell and Lange-Nielsen syndrome. Performing ECGs in schools for deaf children, James ${ }^{11}$ identified two pedigrees with QT prolongation being transmitted in an autosomal dominant manner. However, the ECG irregularities were seen in both deaf and hearing patients and the likely explanation for these observations is the coincidental occurrence of autosomal recessive deafness with RomanoWard syndrome.

That Romano-Ward syndrome is autosomal dominant in its inheritance is indisputable. Indeed positive linkage to chromosome $11 \mathrm{p}$ markers has been shown in a very large Utah family. ${ }^{12}$ However, the prolonged QT intervals in both the maternal and paternal lines in our family could possibly be explained by the Romano-Ward model if both unrelated grandmothers (II.2 and II.4) had the condition. Although precise epidemiological data as to the prevalence of Romano-Ward syndrome are lacking, it is not thought to be a very common disorder and this coincidence therefore appeared unlikely.

QT interval prolongation, however, is an aetiologically heterogeneous disorder. Several distinct and unrelated factors may express themselves in this electrophysiological final common pathway. Among the known causes are metabolic, drug related, and ischaemic events, as well as the two genetically determined conditions. Irrespective of root cause, whenever QT interval is prolonged there is an increased propensity to arrhythmia. ${ }^{13}$ Our observations in this pedigree prompted a reassessment of the relationship between phenotype and genotype in Romano-Ward syndrome. In a single large pedigree, Vincent et al $^{14}$ noted that only $24 \%$ (119/495) of those at $50 \%$ risk of inheriting the gene had QTc $>0.44$ seconds. Thus, only half of those expected to have QT abnormalities did so. The essential message from this is that phenotype cannot be relied upon to predict genotype accurately and that approximately $50 \%$ of gene carriers are undetectable clinically.

This observation may be crucial to the analysis of our pedigree since II 1 has a normal QTc but two of his children (III.2 and III 4 ), as well as two grandchildren (IV·4 and IV·5), have prolonged QTc. None the less, it seems more likely that II $\cdot 1$ is a non-manifesting gene carrier than that his unrelated wife (II.2) is also affected and transmitting the disorder to her sons and grandchildren. If II- 1 is indeed a subclinical gene carrier, then IV.4 and IV.5 
may represent the homozygous state for this condition. The abnormal QTc in II. 2 more probably is the result of one of the other causes of QT prolongation than of genetic factors.

If the phenotype clearly indicates that an at risk subject has inherited the Romano-Ward syndrome then management by beta blockade is effective in reducing arrhythmic events. No cardiac arrest has been reported in such subjects while on this medication. ${ }^{14}$ However, identification of those family members who might benefit from such measures is limited at present to those with a positive phenotype with inevitable omission of subclinical gene carriers.

We present this family to emphasise the problems which have been encountered in its analysis and to underline the difficulty which may attend identification of positive affectation status in the Romano-Ward syndrome. The rogue elements of the deafness, the consanguinity, and the normal QTc all contributed to the general confusion. The case we make is that counselling in this condition based on QTc considerations alone is a hazardous venture.

We wish to thank Dr C Sissons for assistance with ECG investigation of several patients in this report.

1 Moss AJ. Prolonged QT interval syndromes. $f A M A$

2 Bazett HC. An analysis of the time relations of the electrocardiogram. Heart 1920;7:353-70.

3 Fisch C. Electrocardiography and vectorcardiography. In: Braunwald E, ed, Heart disease: a textbook of cardiovascular medicine. 4th ed. Philadelphia: Saunders, 1992.

4 Romano C, Geme G, Pongiglione R. Aritmio cardiache rare dell eta pediatrica. Acessi gincopali pen fibrillazione ventricolase parossistica. Clin Pediatr 1963;45:656-83.

5 Ward OC. A new familial cardiac syndrome in children. $f$ Ir Med Assoc 1964;54:103-6.

$6 \mathrm{McKusick}$ VA. Mendelian inheritance in man. 9th ed. Baltimore: Johns Hopkins University Press, 1990.

7 Jervell A, Lange-Nielsen F. Congenital deaf-mutism, functional heart disease with prolongation of QT interval and sudden death. Am Heart $\mathcal{Y}$ 1957;56:59-68.

8 Fraser GR, Froggatt D, Murphy T. Genetical aspects of the cardio-auditory syndrome of Jervell and Lange-Nielsen cardio-auditory syndrome of Jervell and Lange-Nielsen
(congenital deafness and electrocardiographic abnormal-

9 Jervell A, Thingstad R, Endsjo TO. The surdocardiac syndrome Am Heart $\mathcal{F}$ 1966;72:583-93.

10 Fraser GR. The causes of profound childhood deafness. Baltimore: Johns Hopkins University Press, 1976.

11 James TN. Congenital deafness and cardiac arrhythmias. Am $\mathcal{F}$ Cardiol 1967;19:627-43.

12 Keating M, Atkinson D, Dunn C, Timothy K, Vincen GM, Leppert $M$. Linkage of a cardiac arrhythmia, the Long QT syndrome and the Harvey Ras-1 gene. Science 1991;252:704-6.

13 Schwartz PJ. Locati F, Priori SG, Zaza A. The Long QT syndrome. In: Zipes DP, Jalige J, eds, Cardiac electrophy-
siology. Papers 589-605. Philadelphia: Saunders, 1990.

14 Vincent GM, Timothy KW, Jaiswal D. Seventeen year study of a Romano-Ward Long QT family. Circulation 1989;60(suppl II):654A. 